\title{
Padrões e Mudanças no Financiamento e Regulação do Sistema de Saúde Brasileiro: impactos sobre as relações entre o Público e Privado
}

\section{Patterns and changes in the financing and regulation of Brazilian Health System: impacts on public and private relationships}

\author{
Ligia Bahia \\ Professora Adjunta da Universidade Federal do Rio de Janeiro, \\ Coordenadora do Laboratório de Economia Política da Saúde da \\ UFRJ (LEPS/UFRJ). \\ E-mail: ligiabahiaœterra.com.br
}

Resumo

O trabalho sistematiza as matrizes interpretativas envolvidas no debate sobre o sistema de saúde brasileiro e avança hipóteses sobre as extensas e dinâmicas fronteiras de interseção público-privadas que o caracterizam. Considerando que o hiato entre as concepções sobre o sistema de saúde baseadas em modelos puros e a realidade brasileira, na qual predominam as formas híbridas de prestação e organização de redes de serviços, constitui, per se, um foco permanente de tensões, o estudo destaca e dimensiona: a utilização de fontes públicas de financiamento à demanda e a oferta dos planos de saúde; o afluxo de clientes de planos a uma capacidade instalada de recursos físicos e humanos constituída e reproduzida com recursos públicos; a inserção público-privada de profissionais de saúde e as franquias para dirigentes de empresas privadas assumirem cargos públicos e vice-versa. Os reflexos da estrutura e formas de articulação entre o público e o privado nas agendas dos mais importantes fóruns de debate e formulação de diretrizes para o sistema de saúde, as Conferências de Saúde (previstas pela Lei 8142-90 como instâncias de avaliação e elaboração de diretrizes para a saúde nas três esferas de governo), e das instituições governamentais relacionadas diretamente com o SUS são analisados. Conclui-se que as tensões, conflitos e proposições, sobre o considerado componente público do sistema de saúde, estão direcionadas a arenas específicas de debate. Paralelamente renovaram-se e constituíram-se outros fóruns de negociação sobre o componente privado. Portanto, a segmentação das demandas reflete-se, de maneira quase automática, no âmbito setorial, na definição de "pautas especia- 
lizadas" - ou no público ou no privado.

Palavras Chave: Regulação; Relações entre público e privado; financiamento.

\section{Abstract}

This article systematizes the interpretative matrixes used in the debate about the Brazilian Unified Health System and formulates hypothesis about the extensive and dynamic frontiers of the public-private intersections that characterize it. Considering the gap between the health system concepts based on pure models and reality, where hybrid forms predominate in health services organization, constituting a permanent focus of tensions, the study highlights: the use of public financing sources for the demand and the offer of health plans; the afflux of clients from private health plans to the public health systems physical infra-structure and human capacity; the public-private insertion of health professionals and the permission that administrators of private enterprises occupy public administrative jobs and vice-versa. The consequences of the structure and forms of articulation between public and private in the agenda of the most important forum of debates and the formulation of directives for the Unified Health System, The Health Conferences, and government institutions directly related to SUS are analyzed. The author's conclusion is that the tensions, conflicts and propositions about the public component of the Health System are directed to specific arenas. In parallel other negotiation arenas about the private component were constituted and renewed. Thus, the segmented demands reflect, automatically, in the different sectors, in the definition of special agendas -or in the public or in the private.

Keywords: Regulation, Public and Private Relations, Financing.

\section{Introdução}

O atual sistema de saúde brasileiro, baseado no direito universal à saúde representa uma ruptura com as formas pretéritas de organização das políticas sociais no País. Até o final da década de 8o, os benefícios previdenciários e as instituições de saúde vinculadas ao Ministério da Previdência Social só eram acessíveis para os trabalhadores do mercado formal de trabalho e seus dependentes ${ }^{1}$. As ações do Ministério da Saúde e secretarias estaduais e municipais de saúde destinavam-se precipuamente ao atendimento da parcela da população não coberta pela Previdência Social. A unificação das instituições responsáveis pela saúde, definida pela Constituição de 1988, resultou de um processo de intensa participação social em torno da defesa da saúde como direito de cidadania. A reforma do sistema de proteção de social, inscrita na Constituição de 1988, dirigida a reverter o acentuado padrão de estratificação social, não logrou, contudo, superar obstáculos de caráter estrutural à extensão das políticas de proteção social. A adesão por parte de setores da burocracia governamental à agenda neoliberal, nos anos 9o, tonificou as concepções sobre a concessão de benefícios diferenciados para os mais "capazes" e consequentemente a ampliação da demanda e a oferta de planos privados de saúde.

Como se sabe, a disjunção entre o formal e o real, não é uma exclusividade das políticas de saúde no Brasil $^{2}$. O que confere singularidade à reforma do sistema de saúde brasileiro é que os preceitos de universalização, eqüidade e integralidade da atenção à saúde - que adquiriram estatuto legal, no âmbito de um texto constitucional imediatamente descaracterizado pelo ideário neoliberal, como um obstáculo à integração da economia brasileira nos circuitos globalizados - tenham resistido às tentativas de desidratá-los. Em

\footnotetext{
1 Atualmente a média nacional de cobertura previdenciária para a população ocupada entre 16 a 59 anos é 62,5\%. Essa proporção varia entre as diferentes unidades federadas. Em Santa Catarina, estado situado na região sul a cobertura previdenciária é 75,5\% e no Pará, unidade federada localizada na região norte, 38, 1\% (Brasil - Ministério da Previdência Social, 2004 - estimativas realizadas a partir da análise dos microdados da Pesquisa Nacional por Amostra de Domicílios realizada pelo Instituto Brasileiro de Geografia e Estatística em 2003)

2 O`Donnel (1996) considera que, nos países tais como o Brasil, que inauguram seus processos de redemocratização em condições de desigualdade acentuadas, as fronteiras entre o público e o privado são menos controladas e portanto mais permeáveis aos "particularismos” e à tomada e implementação de decisões em favor de interesses econômicos poderosos e organizados. As democracias delegativas e não representativas (concepção cesarista e plebiscitária de um executivo eleito que por vezes desenvolve esforços para erodir o funcionamento do controle de uma prestação de contas pelas próprias agências públicas) não garantem o conjunto de direitos de cidadania. Os indivíduos são cidadãos em relação às eleições, mas o acesso eqüitativo às agências públicas é franqueado apenas a uma minoria, reproduzindo a disjunção entre o legal e o real.
} 
200o, o Brasil classificou-se em último lugar, em um ranking, baseado em critérios da Organização Mundial de Saúde, para avaliar a eqüidade dos sistemas de saúde na América Latina. O sistema de saúde colombiano, tendo absorvido as recomendações de privatização e individualização do seguro saúde do Banco Mundial, foi considerado o melhor entre os 21 países avaliados (OMS, 200o). Apesar das pressões, as iniciativas para alterar fundamentos legais do SUS, inspiradas pelas promessas de eficiência alocativa, foram barradas. De fato, o processo de redemocratização no Brasil imprimiu à reforma do sistema de saúde uma direcionalidade contrária às diretrizes de retração do papel do Estado na regulação e garantia do acesso à saúde.

Porém, a universalização, embora formalmente amparada pela legislação, vem sendo desafiada pela preservação e reorganização da segmentação do sistema de saúde. A convivência entre o sistema público e os esquemas assistenciais privados adquiriu visibilidade gerando conflitos, na esfera econômica, relativos à competição entre as empresas privadas e, na área de defesa do consumidor, atinentes às garantias de cobertura. Dez anos após a promulgação da Constituição foi aprovada a Lei 9656-98 que regulamenta as empresas de planos e seguros de saúde. A intervenção estatal sobre a atuação das empresas de planos de saúde ampliou as atribuições governamentais sobre um segmento que atua na saúde. Todavia, a importação do modelo agência reguladora ${ }^{3}$ da área econômica - cujos atributos de autonomia e independência decisória visaram atender a opção dos governantes de garantir credibilidade aos investidores no contexto de privatização dos monopólios naturais - não se mostrou inteiramente adequada à institucionalização de novas interfaces entre consumidores e setores regulados ${ }^{4}$. Na saúde, a regulamentação de planos de saúde, via agência reguladora, provocou inicialmente uma cisão institucional entre a Agência Nacional de Saúde Suplementar (ANS) e o Ministério da Saúde.
As interpretações sobre a permanência de uma forte tensão entre o universal e os particularismos no sistema de saúde e seus reflexos nos padrões de financiamento regulação podem ser categorizadas, de maneira simplificada, em duas vertentes. Para alguns autores, autoridades governamentais e entidades integrantes dos processos de formulação e deliberação sobre o SUS, o sub-sistema privado é um obstáculo que será superado em etapas de maior amadurecimento e contextos econômicos mais favoráveis à Reforma Sanitária. Para outros, situados nas empresas privadas de serviços e suas entidades representativas, a expansão da assistência privada comprova a eficiência do mercado e a inviabilidade de que o Estado se responsabilize pela saúde de todos os brasileiros. De acordo com os últimos, o SUS deve estar direcionado para os que "não podem pagar" um plano privado de saúde. 0 corolário dessa assertiva é que os planos de saúde são imprescindíveis, na medida em que "desoneram" o SUS das despesas com a saúde dos mais aquinhoados.

Essas matrizes interpretativas, são úteis para situar o debate e as relações entre atores e interesses envolvidos com o sistema de saúde. No entanto, seus supostos sobre as possibilidades de mudança/manutenção de proporções de demandas para um sistema público ou privado, subscrevem um modelo explicativo que não propicia o destaque das extensas fronteiras de interseção entre o público e o privado. 0 hiato entre as concepções sobre o sistema de saúde baseadas em modelos puros e a realidade brasileira, na qual predominam as formas híbridas de prestação e organização de redes de serviços, constitui, per se, um foco permanente de tensões. Nesse sentido, pouca atenção tem sido dada: à utilização de fontes públicas de financiamento à demanda e a oferta dos planos de saúde; ao afluxo de clientes de planos a uma capacidade instalada de recursos físicos e humanos constituída e reproduzida com recursos públicos; e às franquias para que dirigentes de empresas privadas assumam cargos públicos.

\footnotetext{
3 As agências são unidades organizacionais não atreladas ao organograma do Executivo, mas vinculam-se aos ministérios de suas respectivas áreas de atuação. Seu formato jurídico-institucional (autarquia especial) caracteriza-se pela independência administrativa, ausência de subordinação hierárquica mandato fixo, estabilidade de seus dirigentes e autonomia financeira.

4 As duras críticas elaboradas por setores contrários à privatização das estatais e à estrutura das agências resultaram na elaboração de um Projeto de Lei (PL 3.337/2004) que amplia o controle social e atribui a responsabilidade pela laboração das diretrizes políticas de regulação aos ministérios.
} 
Replicando a aparente dicotomia entre o público e o privado, as agendas de debate dos mais importantes fóruns de debate e formulação de diretrizes para o sistema de saúde, as Conferências de Saúde ${ }^{5}$, e das instituições governamentais relacionadas diretamente com o SUS contemplam as tensões, conflitos e proposições sobre o que é considerado como componente público do sistema de saúde. Paralelamente renovaram-se e constituíram-se outras arenas de debate e negociação sobre o componente privado. Portanto, a segmentação das demandas reflete-se, de maneira quase automática, na definição de "pautas especializadas” - ou no público ou no privado.

Mais recentemente, na esteira das vitórias de candidaturas de esquerda em vários países da América Latina e de um posicionamento de instituições como a OPAS sobre os méritos dos sistemas universais ${ }^{6}$, o debate sobre os êxitos e as contradições do sistema tem contribuído para o aprofundamento da compreensão sobre as relações entre o público e o privado. Por um lado, o reconhecimento da importância do programa de Aids formulado em bases universais e das altas coberturas de terapia renal substitutiva e transplantes e os avanços da arquitetura institucional do SUS - expressos na constituição de instâncias de articulação entre a esfera central do governo com as instâncias sub-nacionais e entre governo e sociedade - contrasta positivamente o Brasil com outros países da América Latina. De outro lado, os gastos públicos com saúde no Brasil, se contabilizados exclusivamente os orçamentos do Ministério da Saúde e das secretariais estaduais e municipais de saúde, são relativamente menores do que os de outros países situados no continente americano7. Além disso, o componente privado do gasto, constituído por duas parcelas: o pagamento de planos privados de saúde e o desembolso direto das famílias com o pagamento de serviços de saúde, medicamentos e outros insumos é maior no Brasil, tendo como referência os mesmos países selecionados.

Portanto, a adição de uma alta proporção de gastos privados com saúde a um desenho universal do SUS representa uma aproximação mais realista à segmentação do sistema de saúde brasileiro. As comparações com outros países da América Latina mostram que, em 2001, a proporção de gastos públicos com saúde no Brasil $(41,6 \%)$ foi semelhante ou menor do que a de países congêneres que optaram por estimular a privatização como o Chile (44\%) e a Colômbia (65,7\%) (WHO, 2004). Essas evidências, contudo, não autorizam afirmações sobre o fracasso do modelo universal brasileiro.

As analogias do SUS com sistemas modelares, das quais derivam assertivas como a semelhança do sistema de saúde brasileiro, no plano formal, ao inglês e, no prático, ao dos EUA, embora de inegável valor heurístico, talvez sejam demasiado genéricas aos propósitos de um exame mais aprofundado sobre os temas regulação e financiamento do sistema de saúde brasileiro. Comprovadamente, as aproximações de uma realidade local específica com a de outros países com contextos histórico-sociais diferenciados e irreproduzíveis são limitadas. Nesse sentido, o exame das especificidades das trajetórias das políticas de saúde não pode prescindir da reflexão sobre o padrão híbrido e competitivo de financiamento e regulação que organiza simultaneamente o SUS e o mercado privado. Contudo, o exame dos temas financiamento e regulação sob esse ângulo exige a mobilização de referenciais analíticos e investigações empíricas rigorosos. Esse trabalho, não enfrenta esse desafio pois se restringe à sistematização de hipóteses que possam contribuir para a ampliação do círculo de interlocução entre estudiosos e os formuladores das políticas de saúde. Mas procura elencar um conjunto de informações para subsidiar a reflexão e o debate sobre os temas financiamento e regulação e seus desenvolvimentos posteriores.

\footnotetext{
5 Previstas pela Lei 8142-9o como instancias de avaliação e elaboração de diretrizes para a saúde nas três esferas de governo.

6 O documento para a Reunión de Consulta de La Región de Las Americas, Acerca del Undécimo Programa de Trabalho da Organizacion Mundial de La Salud, Washington, D.C., EUA, 9 de febrero de 2005 11GPW/Documento de antecedentes No. 1 contém uma reflexão crítica sobre a influência que o Banco Mundial exerceu na política sanitária mundial, considerando o fato de que: o mero racionalismo econômico, as soluções tecnocráticas e as soluções baseadas no co-pagamento dos serviços não reduziram a distância entre ricos e pobres.

70 gasto per capita no Brasil em 2001, equivalente a US\$222, foi menor do que o da Argentina (US\$ 679), Chile (US\$ 303), México (US\$ 327), Uruguai (US\$ 603) e Venezuela (US\$ 307) (WHO, 2004)
} 


\section{Origem e Trajetórias dos Sub-Siste- mas Público e Privado de Atenção à Saúde no Brasil}

A convivência de um sistema de saúde universal com a preservação de coberturas caracterizadas pela organização de subsistemas privados segmentados, segundo critérios de status sócio-ocupacional, diferencia o sistema de saúde brasileiro, tanto daqueles orientados predominantemente pelo mercado, quanto dos caracterizados pelo financiamento público e prestação ou compra de serviços pelas instituições governamentais. A singularidade brasileira não se localiza, propriamente no hibridismo do modelo - presente em quase todos os sistemas de proteção social - mas sim nas interpretações opostas sobre a apropriação das proporções mercado/Estado para justificar a primazia do mercado ou a legitimidade da intervenção estatal na saúde. 0 sistema de saúde brasileiro, quando apresentado pelos integrantes da gestão pública, é visto como emblema de um processo exitoso de extensão de cidadania. Mas para os representantes dos serviços e empresas privadas de comercialização de planos de saúde, o mesmo sistema é o locus de um poderoso mercado privado, movido pela dinâmica da estratificação de benefícios.

As disputas em torno da subordinação/predomínio do componente público sobre o privado na saúde, sob um enquadramento eminentemente conjuntural, são explicadas pela manutenção dos preceitos gerais de uma legislação social avançada combinada com a inflexão na prática de condução do sistema de seguridade social. As perspectivas otimistas sobre as possibilidades, de pelas políticas sociais, reduzir as desigualdades, que vicejaram durante o processo de redemocratização, contrapostas ao ceticismo dos neoliberais que impregnou as autoridades governamentais em toda a América Latina nos anos go resultaram na desfiguração do conceito de Seguridade Social impresso na Constituição de $1988^{8}$. Embora a garantia formal de proteção social permaneça vigente, a legislação que regulamentou a Seguridade Social ignorou a importância da integração das políticas previdenciárias às de saúde e assistência social e impôs a separação das três áreas ${ }^{9}$.

No âmbito da saúde, a superposição de modelos de proteção social afetou os valores e a velocidade de estruturação do Sistema Único de Saúde. O direito universal à saúde ${ }^{10}$, princípio basilar de um Sistema Único de Saúde abrangente e inclusivo, seria assegurado pela ampliação e diversificação das fontes de financiamento da Seguridade Social. Tal aporte adicional de recursos viabilizaria a extensão de coberturas antes, exclusivas aos empregados vinculados ao mercado formal de trabalho e seus dependentes, a todos os brasileiros. Contudo, os constrangimentos econômicos e a adesão, ainda que não incondicional, dos governantes brasileiros às recomendações das agências internacionais ${ }^{11}$ interpuseram sérios obstáculos à implementação do SUS. O desfinanciamento do SUS ${ }^{12}$, conseqüente ao compromisso dos sucessivos gover-

8 No que se refere à Previdência Social, a perspectiva da instituição de fundos de capitalização em contraposição ao regime de repartição simples representa um brutal desvirtuamento do modelo de seguridade social aprovado pela Constituição de 1988 . 0 objetivo de que a Previdência Social seja economicamente eficiente, condição sine qua non para o cumprimento de seu papel central no sistema de proteção social, torna-se destituído de sentido quando dissociado de um padrão de justiça. A coletivização dos riscos reflete e projeta histórias baseadas em culturas de solidariedade e direitos. Por seu turno, as contas previdenciárias individuais, privadas e capitalizadas dificilmente garantirão à maioria da população um nível adequado de bem-estar na velhice, pois uma proporção significativa de cidadãos brasileiros não conseguirá acumular créditos para garantir benefícios de aposentadoria adequados, na medida em que uma parcela considerável dos atuais jovens tem vínculo informal com o mercado de trabalho.

9 A aprovação das Leis Orgânicas específicas entre 1990 e 1993 consolidou a fragmentação e a institucionalização de competências exclusivas de cada área por distintos ministérios. Adicionalmente, as receitas do orçamento da Seguridade foram desviadas e discriminadas.

100 direito universal à saúde está consagrado no artigo 196 da Constituição de 1988 ,

11 Publicação do Banco Mundial de 1993 (Relatório sobre Desenvolvimento Social: investindo em saúde) preconiza a desregulação dos denominados "bens não públicos", isto é, a assistência médico-hospitalar individual, além da descentralização e focalização da oferta de coberturas de "bens públicos", entendidos como pacotes básicos de serviços, para os pobres.

12 As crises decorrentes do "desfinanciamento" da saúde agudizaram-se no período 1994-1995 e foram em parte contornadas com a aprovação de uma contribuição provisória sobre a movimentação financeira (CPMF) que atualmente representa uma das principais fontes de financiamento do SUS. 
nos de obter elevados superávits primários e da "desconstitucionalização" do orçamento da Seguridade Social, comprometeu a premissa de universalidade do acesso à saúde.

À luz de um enfoque que permita divisar um horizonte temporal mais alargado, as relações entre o público e o privado no sistema de saúde, refletem a heterogeneidade estrutural do capitalismo brasileiro. A generalização das relações capitalistas de produção no País e o profundo atraso das dessas relações em um de seus aspectos essenciais - as relações entre capital e trabalho - expressam-se, entre outros indicadores, na informalização dos vínculos trabalhistas (em 2003, apenas $46,4 \%$ da população economicamente ativa contribuía para a Previdência Social; entre os empregados do setor agrícola e não agrícola a proporção de empregados com carteira assinada foi de 30\% e 57,9\% respectivamente) (IBGE, 2004). Vista sob esse ângulo, a dissonância entre a posição que a economia do Brasil ocupa no mercado mundial e a pouca eficácia dos instrumentos de política social explica-se pelos diferenciais de renda da população. A presença de um mercado de planos de saúde relativamente extenso poderia ser encarada como decorrência direta da opção da demanda (os que podem pagar) por serviços privados. Tal postulado é confirmado pela estrutura de distribuição da renda. Em 1999, os rendimentos de $72 \%$ da PEA, aí incluídos os que declararam não auferir renda do trabalho, situaram-se na faixa de até 3 salários mínimos. Após 4 anos, em 2003, essa proporção aumentou para 78,3\%. Consequentemente, não é uma mera coincidência que a proporção de brasileiros vinculados a planos de saúde seja extremamente semelhante à daqueles que auferem mais que três salários mínimos de renda.

Ambas abordagens, não obstante suas raízes e intenções distintas, naturalizam o complexo processo social de construção do sistema de saúde brasileiro ao atribuir aos seus componentes público e o priva- do o status de sistemas autônomos. Da noção evolutiva sobre o processo de implementação do SUS deriva um prognóstico otimista: com o passar do tempo, os atuais problemas de acesso seriam superados progressivamente e não haveria mais necessidade de cobertura de planos privados. A outra perspectiva, em contraste, sinaliza a permanência de uma segmentação perene. A categoria "quem pode pagar", presente nas duas visões, tomada como ponto da clivagem entre o sistema público e o privado, é tomada como uma reedição do padrão assistencial diferenciado aos contribuintes da Previdência Social (mercado formal de trabalho) e aos trabalhadores do mercado informal vigente no País durante o processo de industrialização. Assim, o legado de uma segmentação ainda muito visível e a baixa velocidade das mudanças evidenciam de sobra as razões do padrão estratificado dos direitos sociais no Brasil. Contudo, o detalhamento da atual dinâmica do sistema de saúde e suas tendências de mudança são imprescindíveis a análises mais específicas.

A representação sintética das características da demanda e oferta da assistência médica previdenciária e do SUS, exposta no quadro 1, agrupadas em torno da origem e as trajetórias ressaltam algumas das ambigüidades do sistema de saúde. É importante observar, no que tange à oferta, a permanência da extensa rede de serviços credenciados particulares (privados e filantrópicos) que a Previdência Social no Brasil deixou como herança para o SUS. No que diz respeito à demanda, nota-se o deslocamento de segmentos médios e servidores públicos civis e militares no sentido da adesão aos planos privados de saúde de pré-pagamento (até os anos 70, os segmentos médios remuneravam serviços de saúde diretamente). Sublinha-se ainda que os segmentos, constituídos por trabalhadores informais e seus dependentes, passaram, após a vigência do SUS, a poder acessar os serviços privados credenciados e próprios da previdência social. 


\section{Quadro I - Características da Demanda e da Oferta da Assistência Médica da Previdência Social e do Sistema Único de Saúde}

Previdência Social e Ministério da Saúde (1930 a 1988)

\section{Demanda}

Demanda Formal

Vinculados à Previdência

Trabalhadores urbanos inseridos nas atividades direta ou indiretamente relacionadas com implantação e expansão da Industrialização

Não Vinculados à Previdência

Trabalhadores com vínculos informais ao mercado de trabalho

Demanda por Esquemas

Assistenciais coletivos Alternativos

Trabalhadores urbanos com vínculo com a Previdência Social, inseridos nas indústrias de grande porte dos pólos industriais

Servidores públicos civis e militares

Demanda por Serviços Privados

Remunerados Mediante Desembolso Direto (Camadas médias)

Sistema Único de Saúde (após 1988)

Demanda

Demanda Formal

Cidadãos brasileiros

Demanda por Esquemas

Assistenciais coletivos Alternativos

Servidores públicos civis e militares

Demanda por Serviços Privados

Remunerados Mediante Desembolso Direto

Segmentos sem planos privados de saúde que pagam

consultas "populares"

\section{Oferta}

Serviços Próprios exclusivos para os cobertos pela Previdência Social e serviços privados (hospitais, médicos e unidades de diagnóstico e terapiacredenciados)

Serviços Estatais do Ministério da Saúde e de alguns Estados e Municípios e atendimento para "indigentes" por Santas Casas

Serviços Privados Próprios de empresas de planos de saúde e credenciamento de hospitais e médicos

Serviços Estatais Exclusivos para as FFAA's eservidores civis estatutários

Serviços Privados (hospitais, médicos e unidades de diagnóstico e terapia).

\section{Oferta}

Serviços públicos estatais e hospitais e laboratórios privados ou filantrópicos credenciados

Credenciamento de hospitais, laboratórios e médicos e alguns hospitais de empresas de planos de saúde.

Serviços Estatais Exclusivos para as FFAA's, servidores civis estatutários, adesão a planos de saúde, credenciamento de serviços privados.

Clínicas e unidades de diagnóstico e terapia localizadas em geral na periferia das grandes cidades. 
O acréscimo de elementos do financiamento, inserção institucional e legislação às características da oferta e demanda, dispostos no quadro 2, possibilita a visualização dos arranjos jurídico-legais e financeiros que estruturaram a assistência médica previdenciária e hoje conferem suporte ao SUS. Entre outras notáveis diferenças destaca-se a supressão de uma das fontes de financiamento do SUS, as contribuições previdenciárias. Por outro lado, a participação dos estados e municípios na composição dos gastos públicos com saúde aumentou de $40 \%$ para $47 \%$ entre 2000 e 2002 (Brasil - MS, 2004)

\section{Quadro 2 - Características Institucionais, do Financiamento e da Legislação da Assistência Médica da Previdência Social e do Sistema Único de Saúde}

\begin{tabular}{|c|c|c|c|}
\hline $\begin{array}{l}\text { Instituição Responsável } \\
\text { pela Atenção à Saúde }\end{array}$ & Modelo/ Inserção Institucional & $\begin{array}{l}\text { Financiamento (fontes) e Formas de } \\
\text { Remuneração da Produção de Serviços }\end{array}$ & Legislação \\
\hline $\begin{array}{l}\text { Previdência Social (130 } \\
\text { a 1988) }\end{array}$ & $\begin{array}{l}\text { Seguro Social/ Assistência } \\
\text { Médica Individual Ministério do } \\
\text { Trabalho (1930 a 1965), e } \\
\text { Instituto Nacional de Previdência } \\
\text { Social (1966 a 1976) e Ministério } \\
\text { da Previdência Social (1977 a } \\
\text { 1988) }\end{array}$ & $\begin{array}{l}\text { Contribuição sobre a folha de trabalho de } \\
\text { empregados e empregadores / Pagamento } \\
\text { por procedimentos à rede de serviços } \\
\text { credenciada (tabela de referência contendo } \\
\text { os valores referenciais dos procedimentos) } \\
\text { + Pagamento de funcionários de serviços } \\
\text { públicos e aquisição de insumos }\end{array}$ & $\begin{array}{l}\text { Decretos e Leis de } \\
\text { Criação de Institutos } \\
\text { de Previdência } \\
\text { Decreto de Unificação } \\
\text { dos Institutos } \\
\text { (criação do INPS) }\end{array}$ \\
\hline $\begin{array}{l}\text { Ministério da Saúde } \\
\text { (1930 a 1988) }\end{array}$ & $\begin{array}{l}\text { Centralização: Programas } \\
\text { Verticais de Saúde Pública } \\
\text { Ministério da Educação e Saúde, } \\
\text { posteriormente Ministério da } \\
\text { Saúde }\end{array}$ & $\begin{array}{l}\text { Impostos Gerais/ Pagamento de } \\
\text { funcionários de serviços públicos e } \\
\text { aquisição de insumos }\end{array}$ & $\begin{array}{l}\text { Decreto } 19402 \text { de } 1930 \\
\text { cria o Ministério dos } \\
\text { Negócios da } \\
\text { Educação e Saúde Lei } \\
1920 \text { de } 1953 \text { cria o } \\
\text { Ministério da Saúde }\end{array}$ \\
\hline $\begin{array}{l}\text { Ministério da } \\
\text { Saúdesistema Único de } \\
\text { Saúde (1998 em diante) }\end{array}$ & $\begin{array}{l}\text { Assistência Universal Ministério da } \\
\text { Saúde incorpora a instituição } \\
\text { responsável pela Assistência } \\
\text { médica previdenciária } \\
\text { Descentralização: Criação de } \\
\text { fóruns de articulação de } \\
\text { representantes das diferentes } \\
\text { esferas de governo (Federal. } \\
\text { Estadual e Municipal) e de } \\
\text { participação social (Conselhos de } \\
\text { Saúde) Rede de serviços do SUS } \\
\text { (constituída por estabelecimentos } \\
\text { públicos e privados) }\end{array}$ & $\begin{array}{l}\text { Orçamento da Seguridade Social (na } \\
\text { prática Impostos Gerais provenientes de } \\
\text { contribuições sociais de natureza } \\
\text { tributária). Transferência automática de } \\
\text { parte dos recursos federais para estados e } \\
\text { municípios (repasse fundo a fundo) } \\
\text { Pagamento por grupos de procedimentos à } \\
\text { rede de serviços credenciada (tabela de } \\
\text { referência contendo os valores referenciais } \\
\text { grupos dos procedimentos) + Pagamento } \\
\text { de funcionários de serviços públicos e } \\
\text { aquisição de insumos }\end{array}$ & $\begin{array}{l}\text { Constituição de } \\
\text { 1988Leis } 8080-90 \text { (Lei } \\
\text { Orgânica da Saúde) e } \\
8142-90 \text { Normas } \\
\text { Operacionais } \\
\text { (definem } \\
\text { responsabilidades } \\
\text { dos entes federados e } \\
\text { critérios de alocação } \\
\text { de recursos) }\end{array}$ \\
\hline
\end{tabular}

Do cotejamento das características da organização da demanda e oferta com os arranjos institucionais, legais e financeiros do SUS e dos sistemas que o precederam depreende-se: 1) o fim das barreiras de acesso aos cidadãos brasileiros à rede de serviços de saúde, financiada diretamente com recursos públicos; 2) o inequívoco avanço da formalização do direito à saúde na legislação brasileira e o redesenho dos canais de gestão e alocação de recursos federais para atenção à saúde, que passam a se pautar pela articu- lação entre governo federal, estaduais e municipais; 3) a preservação da composição privada-pública da rede de serviços do SUS e essência das formas de remuneração de serviços; 4) uma reestratificação das demandas (a maior parte da população tem a rede do SUS como única alternativa assistencial, mas a parcela dos segmentos populacionais de maior renda, que passou a integrar a clientela dos planos privados de saúde, ampliou-se e um segmento da população, pouco expressivo em termos numéricos, sem acesso aos 
planos, mas com alguma renda para consumir serviços mediante desembolso direto, dinamizou uma oferta de serviços ambulatoriais e exames de menor custo em “clínicas populares").

Tais avanços e impasses se inscrevem num quadro geral de "novo ciclo da política brasileira" definido como: a liberação da dimensão sistêmica da economia de [contaminações] das intervenções do Estado na organização das relações e conflitos sociais (Werneck Vianna, $2005^{13}$ ). Todavia, as incidências dessas mudanças na saúde não são automáticas. Observa-se, por um lado, a ampliação da participação das unidades federadas e municípios, bem como do Poder Legislativo e do Judiciário no debate e formulação das políticas de saúde. Por outro lado, o afastamento do desenho institucional do SUS e de suas bases de financiamento da parte do sistema considerada - esfera do mercado - é maior do que o instituído pelo modelo de assistência médica previdenciária. 0 deslocamento do SUS da esfera do mercado faz-se notar, em primeiro lugar, na dimensão mercado de trabalho, em função de as contribuições sociais dos trabalhadores não integrarem o orçamento da saúde. Em segundo lugar, a "liberação do mercado" afetou também as relações do Estado com os serviços assistenciais e empresas de comercialização de planos de saúde, que adquiriram maior autonomia, ao estabelecerem relações diretas com as empresas empregadoras e indivíduos.

\section{Dimensões dos Componentes Público e Privado}

A fragilidade dos instrumentos políticos da saúde para reverter os padrões herdados da medicina previdenciária fica evidenciada pela análise das proporções entre as demandas e a oferta de serviços que conformam a rede SUS e o mercado de planos e seguros de saúde. Apesar das profundas mudanças em sua arquitetura, o sistema de saúde brasileiro mantém inalteradas, desde os anos 7o, algumas de suas caracterís- ticas básicas, notadamente a importância de determinados tipos de prestadores privados de serviços. A presença de uma capacidade instalada constituída majoritariamente por hospitais privados e o fato de que a maioria dos médicos brasileiros atuem em consultórios particulares parecem, à primeira vista, excessivos em relação a cobertura de apenas 1/3 da população por planos e seguros privados de saúde.

No entanto, esses mesmos médicos e boa parcela dos hospitais privados também integram a rede do SUS. Na prática é a duplicidade dos prestadores de serviços no atendimento à demanda do SUS e à das empresas de planos e seguros de saúde que organiza a rede assistencial do sistema de saúde no Brasil. A existência de prestadores de serviços "puros" está, paradoxalmente, conectada ou às demandas de planos de saúde de padrão executivo ${ }^{14}$ ou às populações de cidades que só possuem serviços públicos, em geral, localizadas no interior e em regiões de menor renda.

A adaptação da mesma base física de recursos para o atendimento de demandas diferenciadas se concretiza na existência de duas portas de entrada nos hospitais (uma para os clientes do SUS e outra para os de planos e seguros de saúde), no trabalho médico em regime parcial no setor público e ainda no fluxo de clientes de planos de saúde, cujos contratos não propiciam ou dificultam coberturas para determinados procedimentos remuneradas pelo SUS. Os estabelecimentos especializados em diagnose e terapia estão voltados, principalmente, ao atendimento de clientes de planos de saúde. A duplicidade do atendimento às demandas no atendimento de exames de alto custo ocorre em estabelecimentos hospitalares. Em outros casos, como por exemplo a terapia renal substitutiva o SUS remunera praticamente toda a demanda atendida em clínicas privadas ${ }^{15}$.

Uma aproximação da magnitude das relações entre oferta e demanda de serviços e gastos com saúde segundo o tipo de cobertura pode ser visualizada no quadro 3 .

\footnotetext{
13 Werneck-Viannna, L.G 2005. Duas décadas e dois anos de governo Lula. Comunicação pessoal por e-mail

14 Planos de saúde que garantem um valor de reembolso elevado de despesas médicas e acesso aos hospitais definidos como de "primeira linha".

15 O SUS é responsável pela remuneração de procedimentos como a terapia renal substitutiva. A proporção dos pacientes em unidades de diálise, remunerados pelas empresas de planos e seguros de saúde, segundo inquérito realizado pela Sociedade Brasileira de Nefrologia em 31 de dezembro de 1999 foi de apenas $4 \%$ (Sesso, 200o, apud Bahia e col.).
} 
Quadro 3 - Dimensionamento da Demanda, Oferta e Gastos com Saúde segundo Tipo de Cobertura

\begin{tabular}{|c|c|c|c|c|c|c|}
\hline \multirow[t]{2}{*}{ Tipo de Cobertura } & \multirow[t]{2}{*}{ Demanda } & \multicolumn{3}{|c|}{ Oferta } & \multirow{2}{*}{$\begin{array}{l}\text { Gastos com Saúde (3)/ } \\
\text { Faturamento das Empresas ( } 4)\end{array}$} & \multirow{2}{*}{$\begin{array}{l}\text { Estimativa de Gastos } \\
\text { per Capita (5) }\end{array}$} \\
\hline & & Médicos(1) & Hospitais (2) & Diagnose e Terapia (2) & & \\
\hline SUS & $\begin{array}{l}\text { Pelo menos } \\
75 \% \text { da } \\
\text { população }\end{array}$ & $70 \%$ & 78,5 & $29 \%$ & R\$ 46.574 bilhões & $R \$ 264,00^{*}$ \\
\hline $\begin{array}{l}\text { Planos e Seguros } \\
\text { Privados de Saúde }\end{array}$ & $\begin{array}{l}25 \% \text { do } \\
\text { total da } \\
\text { população }\end{array}$ & $67 \%$ & 65,5 & $71 \%$ & R\$27.015 bilhões & $\mathrm{R} \$ 819,00^{* *}$ \\
\hline
\end{tabular}

*Despesas com saúde *Valor Total dos Prêmios Arrecadados

* considerando a totalidade da população ${ }^{* *}$ considerando apenas os clientes de planos de saúde

Fontes:

(1) Conselho Federal de Medicina, 2004

(2) IBGE - Pesquisa Assistência Médico-Sanitária 1999/ IPEA, 2002

(3) Ministério da Saúde, 2004 estimativa de gastos públicos (federal + estadual + municipal)

(4) ANS, 2004

(5) IBGE Estimativa de População 2002 e ANS Cadastro de Beneficiários, Julho de 2003

Essas informações confirmam a desproporção entre a demanda da rede de serviços do SUS (pelo menos $75 \%$ da população da brasileira é atendida exclusivamente pelo SUS) e dos planos e seguros de saúde (cerca de $20 \%$ a $25 \%$ do total de habitantes) relativamente à oferta de serviços disponível e os gastos com saúde para cada segmento. Tais assimetrias e sobretudo a aparente virtualidade da rede disponível ao atendimento dos clientes de planos e seguros pri- vados de saúde, adquirem sentido e contornos mais nítidos, quando detalhadas, como no quadro 4 . A superioridade da oferta de recursos, em particular, de alguns mais especializados/de maior custo para a demanda envolvida com os planos e seguros privados de saúde não é uniforme. Observa-se que a inversão entre demanda e oferta dos equipamentos para a realização de diagnósticos por imagem não ocorre em relação aos equipamentos de hemodiálise.

\section{Quadro 4 - Proporção de Equipamentos Disponíveis aos Segmentos da População Cobertos Exclusivamente pela Rede de Serviços do SUS}

\begin{tabular}{|l|l|}
\hline Ressonância Nuclear Magnética & $28,2 \%$ \\
\hline Mamográfo & $33,7 \%$ \\
\hline Tomográfo & $42,0 \%$ \\
\hline Rx de mais de $500 \mathrm{Ma}$ & $50,0 \%$ \\
\hline Equipamento para Hemodiálise & $79,8 \%$
\end{tabular}

Fonte: IBCE - Pesquisa Assistência Médico- Sanitária 2002

Os diferenciais entre oferta e demanda refletemse nos padrões de utilização de serviços. A proporção dos segmentos vinculados a planos e seguros privados de saúde que tiveram pelo menos uma consulta médica durante um ano foi de $71,9 \%$ e a da população exclusivamente coberta pelo SUS apenas $41,3 \%$. Tal padrão é inverso ao status de saúde: a cobertura de planos de saúde é maior entre os que avaliaram seu estado de saúde como bom ou muito bom $25,9 \%$ é maior do que entre os consideraram seu status de saúde como ruim ou muito ruim 14,5\% (IBGE, PNAD/98).

Essa "seleção favorável”, acompanhada por um padrão de maior utilização de serviços entre os que estão cobertos por planos de saúde, estende-se aos idosos. Lima e col. (2002) demonstraram, por meio de um estudo seccional, que os residentes com idade e" 
6o anos cobertos por planos de saúde apresentaram evidências de melhor condição de saúde, visitaram mais os médicos e usaram um maior número de medicamentos prescritos do que restante dos idosos.

Tal concentração de recursos direcionados para o segmento com maior capacidade de contribuição individual, direta ou indireta, para remunerar os gastos com saúde não se viabiliza apenas pelo aporte de indivíduos e famílias. Os fundos relacionados com os planos privados de saúde que dispõem, relativamente de três vezes mais recursos do que o total do orçamento público destinado ao atendimento do restante da população, originam-se do pagamento de empresas empregadoras e dos gastos das famílias. As conexões das empresas de planos e seguros de saúde com as instituições que pertencem à órbita do mercado de trabalho estabelecem fluxos assistenciais e financeiros aparentemente não articulados àqueles configurados pelo SUS. Porém, a separação entre a organização dos fundos e demandas não prescinde nem de subsídios governamentais e nem do uso comum de parte da oferta de recursos físicos e equipamentos.

\section{Financiamento}

A opacidade das relações entre a esfera pública e privada no sistema de saúde brasileiro, tanto no que concerne à distinção das fontes envolvidas com as receitas quanto na definição da natureza jurídico-institucional dos executores de despesas, dificulta a identificação de "quem paga", "quem recebe os benefícios" e "quem é pago", tal como propõe Evans (2001). No entanto, as tentativas de analisar a estrutura de financiamento, considerando pelo menos a origem dos re- cursos e seu destino a partir de estimativas, ainda que provisórias, contribuem para problematizar o tema regulação na saúde.

O debate sobre progressividade/regressividade do financiamento para a saúde no Brasil tem sido conduzido em três planos distintos. 0 mais geral, tem como tema principal a importância da implementação dos princípios e do orçamento da Seguridade Social e as iniciativas para impedir o desvio de suas receitas. Um dos mais importantes pontos da pauta sobre a Seguridade Social é a criação do Fundo Social de Emergência, em 1994, e a atual Desvinculação de Receitas da União (DRU), que facultam a subtração de $20 \%$ da arrecadação das receitas da Seguridade, destinando-a em quase sua totalidade ao pagamento dos encargos financeiros da União.

Em um plano intermediário, o tema financiamento da saúde está sendo enfocado a partir da regulamentação da Emenda Constitucional $29^{16}$ de 2000 que define um percentual definitivo da receitas da União e dos estados e municípios para a saúde. Atualmente, o Ministério da Saúde e seu principal interlocutor o Conselho Nacional de Saúde vem conduzindo o processo de defesa da vinculação de recursos para a saúde. A expectativa do estabelecimento de fontes estáveis para o financiamento público da saúde e maior grau de autonomia das esferas sub-nacionais na definição e implementação de políticas de saúde articula interesses e agentes, que em outras arenas de negociação situam-se em lados opostos ${ }^{17}$.

Um terceiro plano de equacionamento do papel do financiamento da saúde, vis-à-vis o potencial de redistribuição dos recursos, ressalta a tensão entre o caráter descentralizado do SUS e a hegemonia fiscal da

16 A expectativa fixada nas disposições transitórias da Constituição de 88, de que $25 \%$ da receita de contribuições da Seguridade Social fosse destinada para o financiamento de origem federal das ações e serviços de saúde foi objeto de dispositivos legais buscando estabelecer um percentual definitivo. Os então deputados Eduardo Jorge e Waldir Pires apresentaram emenda à Constituição nesse sentido, que não logrou progresso no Congresso até que o ministro José Serra retomasse uma modificação da emenda, finalmente aprovada, a Emenda Constitucional 29/20oo, que manteve a vinculação das receitas de estados e municípios em 12 e 15 por cento respectivamente, mas rompeu a dedicação das contribuições sociais à Saúde, fixando apenas o seu crescimento a variações do PIB. Se essa emenda, por um lado, permitiu uma estabilidade de receita, por outro quebrou de vez a idéia de financiamento solidário da seguridade e dificultou acréscimos superiores à variação do PIB.

17 As entidades que vem protagonizando o processo de elaboração e defesa da regulamentação da EC 29 são: o Conselho Nacional de Secretários Estaduais de Saúde (CONASS), o Conselho Nacional de Secretários Municipais de Saúde (CONASEMS), os parlamentares que integram a Comissão de Seguridade Social da Câmara Federal e a Comissão de Assuntos Sociais do Senado e a Associação dos Membros dos Tribunais de Contas (ATRICON). A defesa da garantia da ampliação e estabilidade do orçamento público para a saúde aglutina a denominada "bancada da saúde", que reúne parlamentares independentemente de sua orientação partidária. Tal articulação tem sido importante para enfrentar sucessivos embates com a área econômica do governo como: a tentativa de "congelamento" do orçamento do orçamento do Ministério da Saúde em 2001. 
União, considerando os resultados das políticas de alocação de recursos federais. Ugá e col. (2003) concluem que os avanços do processo de descentralização e da expansão das ações de atenção básica acarretaram uma reorientação dos recursos financeiros, refletida na maior homogeneidade na distribuição dos recursos per capita para as unidades federadas e regiões do País. No entanto, esses autores argumentam que a medição dos diferenciais dos per capita estaduais em relação à média nacional não eliminam as iniqüidades na alocação de recursos. A persistência de desequilíbrios na alocação de recursos para assistência hospitalar e ambulatorial entre estados das regiões Sul, Sudeste e do Distrito Federal em relação às regiões Norte e Nordeste pauta os debates sobre a elaboração de critérios para alocação dos recursos de custeio e adoção de programas de investimento que tenham por objetivo reduzir os diferencias inter e intraregionais.

Depreende-se, portanto, que o tema financiamento é complexo e as diferentes perspectivas por meio das quais tem sido abordado conectam-se, ainda que não automaticamente, aos grupos de interesse e orientações normativas presentes nas arenas setoriais e na produção acadêmica. A abordagem simplificada da estrutura e dinâmica do financiamento baseada na estimativa de receitas e despesas não substitui a riqueza da reflexão já acumulada. Assim, a sistematização resumida das informações sobre a origem e o destino dos recursos financeiros envolvidos com o sistema de saúde, contemplando as fontes e entidades públicas e privadas que são remuneradas deve ser encarada apenas como um atalho que conduz a uma observação panorâmica das relações entre financiamento e regulação.

\section{Receitas}

As receitas do sistema de saúde provêem, fundamentalmente, de três fontes de financiamento: os impostos e contribuições sociais; gastos diretos das famílias e gastos das empresas empregadoras. As informações sobre as duas primeiras parcelas são precisas. Mas, as informações sobre os gastos das empresas empregadoras com planos de saúde e medicamentos para seus funcionários não estão disponíveis. Ainda assim, é possível realizar uma aproximação à orientação de Evans (idem) para identificar as receitas provenientes de impostos gerais (IG), planos privados de saúde (PPS) e do desembolso direto das famílias (DD) (outof-pocket) envolvidos com as despesas assistenciais, medicamentos e materiais de tratamento.

Para tanto, considera-se que a primeira parcela IG está constituída pelos gastos com saúde da União, das unidades federadas e dos municípios. A segunda variável da equação PPS representa a soma de parte dos gastos das famílias relativos as despesas com planos privados de saúde com uma estimativa dos gastos das empresas empregadoras com planos privados de saúde, calculada a partir do faturamento declarado pelas empresas de planos e seguros de saúde. A terceira parcela DDF contabiliza os gastos diretos das famílias com saúde exceto aqueles relacionados com o pagamento de planos privados de saúde.

A estrutura da composição das receitas para a saúde em 2003 exposta na tabela 1 evidencia a predominância das despesas de caráter regressivo tais como o desembolso direto e os planos privados de saúde em contraste com a participação de apenas $41,2 \%$ das fontes, com maior potencial de redistributividade, provenientes de impostos gerais. 
Tabela I - Estimativa dos Gastos com Saúde segundo Fontes Públicas e Privadas

Brasil, 2002-2003 em milhões de Reais

\begin{tabular}{|c|c|c|c|c|}
\hline & Fontes & em milhões de R\$ & $\%$ & $\%$ do PIB*** \\
\hline \multirow{4}{*}{ IG } & Impostos Gerais e Contribuições Sociais* & 46.574 & 41,2 & 3,5 \\
\hline & União & 24.737 & 53,1 & \\
\hline & Estados & 10.078 & 21,6 & \\
\hline & Municípios & 11.759 & 25,2 & \\
\hline \multirow{3}{*}{ PPS } & Planos Privados de Saúde** & 25.063 & 22,2 & 1,9 \\
\hline & Gastos das Famílias & 14.069 & 56,1 & \\
\hline & Gastos das Empresas Empregadoras & 10.994 & 43,9 & \\
\hline \multirow{2}{*}{ DD } & Desembolso Direto*** & 41.336 & 36,6 & 3,1 \\
\hline & Total & 112.973 & 100 & 8,6 \\
\hline
\end{tabular}

Fontes:

* Brasil - Ministério da Saúde, 2004

** IBGE- Pesquisa de Orçamento Familiares 2002-2003 e Agência Nacional de Saúde, 2004. A estimativa dos gastos das empresas foi calculada por meio da subtração dos gastos das famílias com planos privados (exceto 10\% considerados como despesas com o pagamento de planos particulares de funcionários públicos) do faturamento declarado pelas empresas de planos e seguros de saúde

***IBGE- Pesquisa de Orçamento Familiares 2002-2003

A estimativa do desembolso direto foi calculada a partir das despesas das famílias com assistência à saúde excetuando as referentes ao pagamento de planos privados de saúde

**** PIB em $2002=$ R\$1.321.400 milhões

De fato, a elevada proporção de despesas com saúde das famílias de classes de menores rendimentos evidencia a regressividade do sistema de financiamento do sistema de saúde brasileiro. Os gastos com medicamentos das famílias situadas nas classes de rendimentos mais elevados são relativamente menores do que os efetuados pelas mais pobres. As famílias cujos rendimentos não ultrapassam
R\$6oo,oo despendem relativamente o dobro de gastos com medicamentos se comparadas àquelas melhor aquinhoadas. Os gastos com planos e seguros de saúde conformam uma tendência contrária a dos gastos com medicamentos - nas famílias com maiores rendimentos (acima de $\mathrm{R} \$ 1600,00$ ) tais despesas representam, em média, $1,5 \%$ a $2,5 \%$ do total (gráfico 1).

\section{Gráfico I - Proporção de Despesas com Assistência Médica por Classes de Rendimento das Famílias Brasil, 2002-2003}

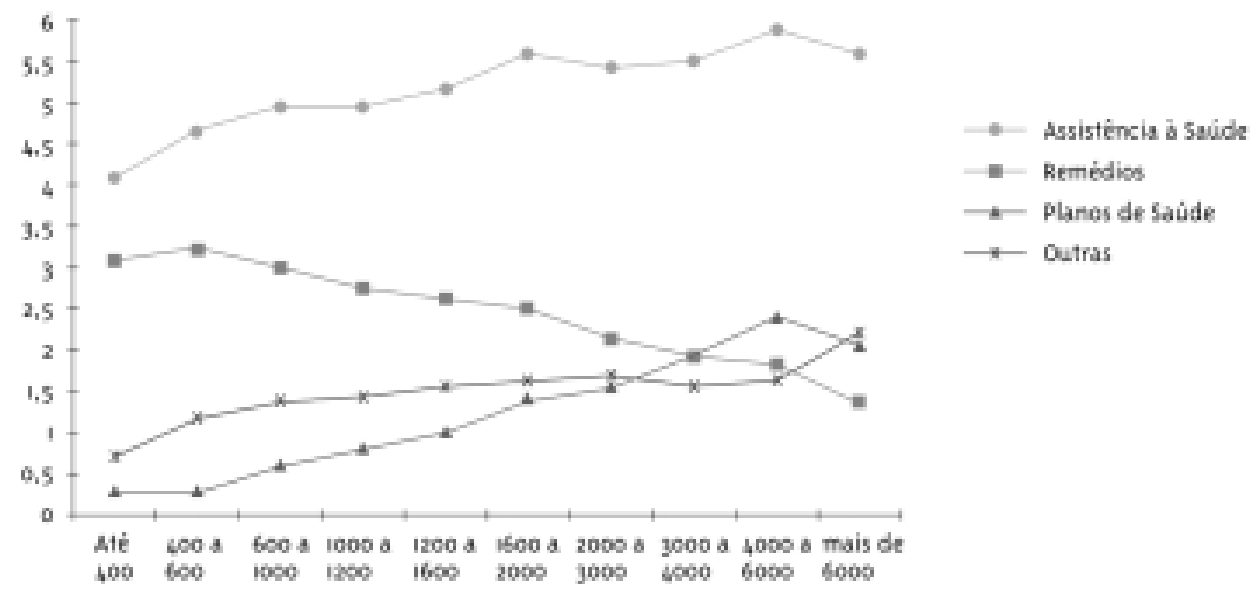


$\mathrm{O}$ aporte de recursos provenientes do desembolso direto, correlacionado diretamente com o uso de serviços e do pagamento de planos privados, cujos preços em tese fixados pela expectativa do risco, beneficia os saudáveis e com maiores rendimentos. Esse panorama vem sendo descrito na literatura como típico dos países em desenvolvimento. Para o Brasil, a permanência de um padrão altamente regressivo no financiamento da atenção à saúde, contraditório com os princípios do SUS, desautoriza a implementação das diretrizes de universalidade, equidade, integralidade e participação social.

\section{Despesas}

A definição sobre o destino dos recursos empregados na saúde é uma tarefa ainda mais árdua do que a estimativa das receitas. Atualmente, estão sendo envidados esforços para estruturar um sistema de Contas em Saúde ${ }^{18}$, que tem por objetivo fornecer informações mais detalhadas sobre o financiamento setorial. Mas, por hora, as possibilidades para delinear um fluxo de recursos que conecte as fontes de receitas aos que são pagos com esses recursos são muito limitadas.

Entretanto, é plausível supor que uma parcela importante dos gastos com saúde seja revertida na remuneração de prestadores privados de serviços de saúde. Tal hipótese justifica-se, a par do padrão dual e regressivo de financiamento, pela predominância dos prestadores de serviços privados no País, inclusive na rede assistencial hospitalar do SUS.

O quadro 4 expõe uma simulação dos fluxos entre as receitas e despesas do sistema de saúde brasileiro construída com base na estrutura de despesas do Mi- nistério da Saúde, seguradoras privadas de planos de saúde e sob o suposto de que os gastos diretos das famílias com assistência médica e hospitalar são integralmente destinados à remuneração de prestadores privados de serviços. Assim, a estrutura de despesas do Ministério da Saúde ${ }^{19}$ é tomada como proxy para a definição do destino de todos os recursos oriundos de fontes públicas, a estrutura de despesas das seguradoras de planos de saúde ${ }^{20}$ é o parâmetro para distribuir o total dos recursos envolvidos com os gastos com planos privados de saúde. Os dados sobre as despesas assistenciais e com insumos provenientes dos gastos diretos das famílias, extraídos da Pesquisa de Orçamento Familiares são fidedignos. Foram consideradas apenas os seguintes itens agregados de despesas: assistência hospitalar; assistência ambulatorial (inclui o atendimento médico e os serviços de apoio ao diagnóstico e terapia em estabelecimentos públicos e privados para pacientes externos e o atendimento em consultórios médicos particulares); medicamentos para pacientes externos e outras despesas.

A estimativa das despesa agregadas por tipo e natureza da rede assistencial envolvida com a prestação dos serviços sugere que não apenas as desproporções entre as proporções da oferta e demanda tornamse ainda mais assimétricas em função dos valores diferenciados das receitas e dos valores de remuneração distintos que caracterizam a segmentação do sistema de saúde no Brasil. Os prestadores de serviços privados (hospitais, ambulatórios e unidades de apoio diagnóstico e terapêutico) são destinatários de $65 \%$ dos recursos manejados pela rede de prestação de serviços e de pelo menos $37 \%$ do total do montante de receitas do sistema de saúde (quadro 5 ).

18 Está sendo desenvolvido pelos pesquisadores do IPEA e do IBGE.

19 A proporção de despesas utilizadas para distribuir as receitas provenientes das fontes públicas tem como referência o estudo de Ugá et al. (2003).

20 As proporções de despesas utilizadas para distribuir as receitas provenientes do pagamento de planos privados de saúde foram estimadas a partir de informações da Fenaseg, 2003. 
Quadro 4 - Despesas com Saúde segundo Tipo de Assistência - Brasil 2002-2003

\begin{tabular}{|c|c|c|c|c|}
\hline Receitas & em R\$ & Estrutura de Despesas & $\%$ & Despesas \\
\hline \multirow[t]{4}{*}{ Impostos Gerais e Contribuições Sociais } & \multirow[t]{4}{*}{46.574} & Assistência Hospitalar & 28,9 & 13.465 \\
\hline & & Assistência Ambulatorial* & 37,7 & 17.555 \\
\hline & & Medicamentos** & 4,9 & 2.271 \\
\hline & & Outras & 28,5 & 13.283 \\
\hline \multirow[t]{2}{*}{ Planos Privados de Saúde } & \multirow[t]{2}{*}{25.063} & Assistência Hospitalar*** & 35,0 & 8.772 \\
\hline & & Assistência Ambulatorial**** & 65,0 & 16.291 \\
\hline \multirow[t]{4}{*}{ Desembolso Direto } & \multirow[t]{4}{*}{41.336} & Assistência Hospitalar & 7,4 & 3.069 \\
\hline & & Assistência Ambulatorial & 12,7 & 5.259 \\
\hline & & Medicamentos & 54,3 & 22.481 \\
\hline & & Outras & 25,6 & 10.526 \\
\hline Total & 112.973 & & & 112.972 \\
\hline
\end{tabular}

Fontes:

Brasil - Ministério da Saúde, 2004

Agência Nacional de Saúde, 2004

IBGE - Pesquisa Nacional de Orçamento Familiares 2002-2003

*Inclui gastos com exames diagnósticos e terapias para pacientes externos assistência farmacêutica (medicamentos básicos)

** Medicamentos estratégicos e excepcionais (medicamentos para AIDS e imunossupressores entre outros)

*** Exclui os gastos com honorários médicos de pacientes internados (estão contabilizados no item assistência ambulatorial)

**** Inclui gastos com exames diagnósticos e terapias para pacientes externos (os planos privados de saúde, em geral, não propiciam cobertura para assistência farmacêutica)

\section{Quadro 5 - Estimativa de Despesas por Tipo de Assistência e Nattureza Jurídica da Rede Assistencial Reponsável pela Cobertura}

\begin{tabular}{|l|l|l|l|}
\hline \multirow{2}{*}{ Tipo de Despesa } & \multicolumn{2}{|c|}{ Rede Assistencial } & \multirow{2}{*}{ Total } \\
\cline { 2 - 3 } & Pública & Privada & 25306 \\
\hline Assistência Hospitalar* & 4917 & 20389 & $100 \%$ \\
\hline Assistência Ambulatorial** & $19 \%$ & $81 \%$ & 39105 \\
\hline$\%$ & 17555 & 21550 & $100 \%$ \\
\hline Medicamentos para Pacientes Externos** & $45 \%$ & $55 \%$ & 24752 \\
\hline$\%$ & 2271 & 22481 & $100 \%$ \\
\hline Outras Despesas & $9 \%$ & $91 \%$ & 23809 \\
\hline \% & 13283 & 10526 & $100 \%$ \\
\hline Total & $56 \%$ & $44 \%$ & 112972 \\
\hline$\%$ & 38026 & 74946 & 100 \\
\hline
\end{tabular}

${ }^{*}$ Considerou-se que 70\%, $10 \%$ e $100 \%$ dos recursos públicos, dos planos privados de saúde e do desembolso direto das famílas são destinados à remuneração dos estabelecimentos privados

** Considerou-se que $100 \%$ dos recursos públicos são destinados à remuneração dos estabelecimentos públicos (embora se saiba que parte desse montante é utilizado para a remuneração de estabelecimentos privados como por exemplo os de hemodiálise). Considerou-se ainda que $100 \%$ dos recursos dos planos de saúde e do desembolso direto das famílias são destinados à remuneração de estabelecimentos privados

*** Os recursos destinados a rede pública envolvida com assistência farmacêutica estão subestimados em função de terem sido calculados apenas com base nos gastos do Ministério da Saúde com medicamentos estratégicos e excepcionais. 
A formulação de Evans (ibidem) sobre as coalizões de interesses entre os "ricos e saudáveis" e prestadores privados de serviços de saúde adquire um significado específico no Brasil em função da forte presença dos interesses privados. As informações sobre as receitas e despesas do sistema de saúde sinalizam que a rede assistencial privada no País não tem sido apenas uma "válvula de escape" ou um ponto de apoio para pressionar e aumentar os valores de remuneração dos serviços. Existem indícios de um fenômeno contrário: os vínculos privados seriam atualmente os responsáveis pela maior parcela da remuneração dos profissionais e de grande parte dos estabelecimentos de saúde, especialmente os que dispõem de maior capacitação tecnológica. Portanto, a ligação de prestadores de serviços à rede do SUS - excetuando-se aqueles dedicados integralmente ao serviços públicos e/ ou aos segmentos populacionais que não estão cobertos pelos planos de saúde e nem dispõem de recursos para remunerar diretamente o serviço prestado - é motivada pela garantia de recebimento de valores fixos (quando de trata de salários dos profissionais de saúde) e repasses dos recursos sem atrasos e glosas indevidas (quando se trata de hospitais).

Isso não significa dizer que nas arenas de debate e negociação, específicas do SUS, os interesses econômicos de prestadores de serviços e dos produtores de insumos e equipamentos estejam ausentes. 0 poder de compra (monopsônico) do SUS, bem como sua capilaridade em todo o território nacional e a importância política da saúde asseguram-lhe um papel de destaque nas agendas governamentais. Esse protagonismo, no entanto, tem sido intensamente disputado pelos empreendedores privados (médicos, empresas de comercialização de planos privados, hospitais, laboratórios e unidades de terapia).

\section{A Regulação}

As coalizões de interesses que gravitam em torno do SUS e do sub-sistema privado de saúde são bastante distintas. A pauta dos defensores da universalização dos direitos de cidadania está constituída pela ampliação e estabilidade do orçamento para a saúde e definição de critérios para alocação de recursos federais às instâncias sub-nacionais. Por sua vez, os prestadores privados de serviços e empresas de planos de saúde clamam pela "desregulação" e/ou pela intervenção estatal para garantir valores mais altos de remuneração dos serviços e redução de impostos. 0 sub-conjunto de interseção dessas agendas é a defesa de mais recursos financeiros para a saúde, sejam esses oriundos de impostos diretos, sejam provenientes de renúncias e deduções fiscais. A despeito de suas especificidades, essas pautas são pouco sensíveis às demandas pela ampliação da equidade. Nem os consensos constituídos em função de compromissos abertos ou indiretos com as demandas por serviços privados e suas respectivas ofertas, nem as coalizões formadas pela defesa do aporte dos recursos para as áreas sociais estão voltados, prioritariamente, à ampliação da efetividade das ações da saúde.

Por outro lado, movimentos sociais, profissionais de saúde, entidades de defesa do consumidor e o Poder Judiciário e autoridades governamentais da saúde e de outras áreas sociais posicionam-se e impõem um debate sobre temas relacionadas com o direito a saúde. Essa agenda, embora menos visível do que a articulada em torno do debate sobre o financiamento, prioriza os temas equidade e integralidade da atenção à saúde. Nesse âmbito, entidades de pacientes com patologias especiais, os movimentos anti-manicomiais, as ONGs que defendem o atendimento integral aos HIV positivos, as entidades feministas e as de profissionais de saúde da família, entre outras, exigem respostas à demandas particulares, porém coletivas e de certa maneira portadoras de novas possibilidades de relações entre cidadãos e Estado. 0 carro-chefe da defesa dos direitos cotidianos dos cidadãos à saúde tem sido o Poder Judiciário. A garantia de direitos à coberturas mesmo aquelas não previstas nos contratos de planos de saúde e na ausência da oferta do serviço ou insumo na rede pública - emanada dos tribunais e do Ministério Público contraria frontalmente a lógica de definição de prioridades do sistema público e associação entre contribuição e benefícios do sistema privado.

0 encaminhamento paralelo das agendas de defesa dos direitos universais e particulares na saúde ganhou terreno no contexto da reforma do Estado, que teve por finalidade impulsionar o modelo econômico orientado para o mercado. As novas modalidades de intervencionismo estatal, caracterizaram-se pelo fato de que ação coletiva fosse pautada pela lógica da competitividade. A ênfase na definição de regras de 
gestão de prestação de serviços e de recursos transferidos à iniciativa privada deslocou a centralidade do Poder Executivo como instância de defesa dos direitos de cidadania (Boschi e Lima, 2002). A ampliação do acesso da sociedade civil ao Legislativo e ao Judiciário redefiniu os espaços institucionais de debate e decisão sobre saúde. Num outro sentido, os grupos de interesses passaram a atuar transversalmente às esferas dos poderes constituídos e a pautar as agendas de trabalho do Ministério e secretarias de saúde, do Poder Legislativo e do Poder Judiciário.

Os novos recortes público/privados que emergem da interpenetração da lógica do mercado na dinâmica de funcionamento do Estado incidem sobre as agendas do do sub-sistema privado e do SUS. Por um lado, a fragmentação das reivindicações e a possibilidade de apropriação diferenciada do espaço público por interesses privados faz-se notar especialmente na atuação legitimada de lobbies de empresas e prestadores de serviços de saúde privados junto ao Legislativo. Por outro lado, a criação de novas entidades de defesa dos interesses de pacientes e consumidores e a capacidade de mobilização e organização de demandas podem conferir maior autonomia ao Estado para processar e assegurar direitos universais.

\section{A Agenda e os Instrumentos de Regulação do SUS}

A agenda do SUS articula-se em torno de três eixos principais. $O$ primeiro se refere aos desafios mais gerais entre os quais situam-se as demandas pela implementação do direito à saúde e ampliação do financiamento e seus temas são conduzidos em diversas arenas de debate e deliberação. 0 segundo eixo aglutina os processos da montagem institucional do SUS a partir das relações intergovernamentais entre os entes federados, que emanam do Ministério da Saúde e das secretarias estaduais e municipais de saúde. Os programas assistenciais, de ampliação de coberturas/ acesso constituem o terceiro, mas não menos importante, grupo de temas prioritários do SUS.

A mais completa plataforma das demandas para o SUS está elencada no Relatório da XII Conferência Nacional de Saúde (CNS, 2005). Esse documento rea- firma a defesa dos princípios dos direitos sociais plasmados na Constituição de 1988, avança proposições mais gerais como a elaboração e aprovação de um Código de Defesa dos Usuários do SUS e detalha a necessidade de desenvolver/ ampliar programas para grupos populacionais específicos como a população indígena, a população negra, os deficientes físicos, os HIV positivos, os idosos etc. Contém ainda proposições sobre o combate à violência e a necessidade de estabelecer e aprofundar a ação do Poder Judiciário na defesa do direito à saúde. Entre esse conjunto de temas, o ponto de pauta que articula uma ampla aliança entre o corpo técnico do Ministério da Saúde, secretários de saúde e prefeitos, a denominada "bancada parlamentar da saúde", instâncias do Poder Judiciário e movimentos sociais é a regulamentação da vinculação de recursos para a saúde.

Em instâncias específicas de debate e deliberação sobre o SUS, as agendas relacionadas com a implementação do SUS são pormenorizadas. O Conselho Nacional de Secretários Estaduais de Saúde (Conass), por exemplo, defende uma ampliação do orçamento do Ministério da Saúde para o exercício de 2005. A justificativa do pleito do Conass é a necessidade do incremento de recursos para assistência farmacêutica básica, medicamentos excepcionais e serviços de alta e média complexidade (Conass X). O Conselho Nacional de Secretários Municipais de Saúde (Conasems) reivindica a melhoria da qualidade da atenção à saúde por meio do investimento em centrais de agendamento de consultas e internações, realização de concursos públicos para a contratação de profissionais de saúde e conseqüente desprecarização dos vínculos de trabalho da força de trabalho que atua na saúde e respeito à diversidade dos arranjos intermunicipais e inter-regionais que poderão constituir-se no processo de regionalização e redefinição de responsabilidades pela atenção à saúde.

As prioridades assistenciais do Ministério da Saúde: melhoria da qualidade e humanização da atenção à saúde, ampliação de coberturas para atendimentos de urgência e a oferta de medicamentos subsidiados (Farmácia Popular ${ }^{21}$ ), dado seu protagonismo na

210 Programa Farmácia Popular é visto com reservas pelo Conselho Nacional de Secretários Estaduais de Saúde e por pesquisadores da área de saúde coletiva. As críticas às farmácias populares baseiam-se na premissa sobre a gratuidade do medicamento prevista pelo SUS em contraposição à venda, com descontos, efetuada pelas farmácias populares. 
estruturação do SUS, inspiram a adoção de programas similares pelas unidades federadas e municípios. Outra vertente de atuação do Ministério da Saúde é a condução do processo de descentralização. Nos anos 90 as Normas Operacionais Básicas (NOB's) ${ }^{22}$ regularam os aspectos de divisão de responsabilidades, relações entre gestores e critérios de transferência de recursos federais para estados e municípios. Atualmente, os efeitos de atomização e competição por recursos decorrentes da expansão de cidades de pequeno porte (10.000 a 20.00o hb), da pouca ou nenhuma capacidade de arrecadação desses municípios associados a uma "paralisia" induzida nos governos estaduais mobilizam os dirigentes do SUS a buscar alternativas a denominada "municipalização autárquica" $\left(\right.$ Dain, 2001) ${ }^{23}$. Assim, a definição de instrumentos de regulação da estruturação de redes assistenciais que sobrepassem os limites municipais e a ampliação das responsabilidades das unidades federadas passam a integrar a pauta do SUS.

A participação dos Poderes Legislativo e Judiciário na estruturação e reorganização do SUS é relevante e bastante diferenciada. No entanto, o espaço de atuação dessas instâncias delimita-se ao debate e posicionamento sobre os temas gerais ou pela garantia do direito à cobertura. A regulação das relações entre os entes federados tem sido uma prerrogativa, quase que exclusiva, do Poder Executivo. O Legislativo constitui-se como uma das principais arenas de formulação e negociação da regulamentação do financiamento da saúde. Por seu turno, as atuações do Poder Judiciário e do Ministério Público são marcadas pela concessão de liminares e mandatos judiciais que asseguram a cobertura imediata, exigem o funcionamento dos serviços de saúde, determinam a impropriedade das formas de contratação de pessoal etc.

A sinergia entre determinadas demandas não impede a "competição" entre as prioridades da agenda do SUS. A montagem de sistemas regionalizados, baseados na garantia de acesso e resolutividade das ações de saúde e de certo modo o encaminhamento das pro- posições sobre financiamento e garantia de direitos universais, disputam, tradicionalmente, espaços com as prioridades governamentais relacionadas com a implantação de programas assistenciais verticais. Portanto, os conflitos entre uma agenda estruturante e as prioridades conjunturais de sucessivos governos que necessitam legitimar-se, pela visibilidade de ações assistenciais implementadas centralizadamente tensionam permanentemente o SUS.

\section{A Agenda e os Instrumentos de Regulação do Sub- Sistema Privado de Saúde}

Pode-se dizer que a repercussão das demandas dos prestadores de serviços privados e as reclamações das empresas de comercialização de planos de saúde é muito mais extensa do que a importância do sub-sistema privado para o atendimento da população brasileira. O poder de organização e a capacidade de vocalização de interesses dos setores componentes da oferta e das clientelas de estabelecimentos e empresas de planos de saúde movimentam diversos fóruns de debate e deliberação sobre as políticas de saúde.

Em termos gerais, as solicitações dos prestadores de serviços e empresas de planos de saúde concentram-se em torno do debate sobre a legitimidade e intensidade da intervenção governamental. Ancorados em conceitos sobre os benefícios da liberdade de trocas entre vendedores e consumidores os representantes das empresas de planos de saúde questionam a legislação referente a regulamentação das atividades de suas empresas. 0 outro foco de conflitos é disputa entre os prestadores de serviços (médicos, hospitais e unidades de diagnóstico e terapia) e empresas de planos de saúde pelos valores de remuneração das atividades assistenciais.

Esses dois pontos de debate, embora referentes no primeiro caso as tensões entre as empresas privadas e a intervenção estatal e no segundo as divergências no âmbito do próprio mercado, convergem em torno de discursos sobre as responsabilidades governamentais sobre a redução ou estagnação do mercado priva-

22 NOBo1/91, NOBol/92, NOB o1/93, NOB o1/96 e NOAS/2001. Pode-se dizer sinteticamente que as NOBs procuraram regular as contradições entre as diferentes esferas de governo por meio de instrumentos de gestão e financiamento permeáveis ao estabelecimento de relações intergovernamentais cooperativas. A criação das Comissões Intergestoras (Triparite e Bipartite) que contam com a participação dos Conselhos de Secretários Estaduais e Municipais de Saúde (Conass e do Conasems) e a transferência automática de uma parte dos recursos federais, segundo critérios de alocação per capita, propiciaram uma efetiva descentralização.

23 DAIN S. Riscos na Regulamentação da E. C. 29. Mensagem pessoal recebida pela autora em 23/04/2004. 
do. De acordo com os executivos das empresas de planos de saúde, as regras sobre cobertura e reajustes dos preços dos planos de saúde da Lei 9656-98 impedem a expansão das clientelas em função da elevação dos valores dos prêmios e resultam na sub-remuneração de serviços prestados.

Nesse quadro, o chamado às responsabilidades governamentais para a edição de normas de alívio fiscal e abertura de linhas de crédito, unindo prestadores de serviços e empresas de planos de saúde, é considerado natural. Paradoxalmente, as contradições entre as demandas pela não intervenção estatal e os clamores pela extensão dos subsídios fiscais às empresas privadas de saúde não se constituem como problema para o sistema de saúde. O financiamento indireto da oferta e demanda por serviços privados vem sendo tratado como objeto privativo da área econômica.

As normas governamentais também são requeridas quando atendem um dos lados da disputa. A reivindicação que vem mobilizando a categoria médica em todo o País é a adoção de uma nova tabela de remuneração e a intervenção governamental para garantir o repasse do aumento das mensalidades dos planos ou seguros de saúde fixados pela Agência Nacional de Saúde Suplementar para os procedimentos cobertos pelas empresas de assistência suplementar. Em tese, as entidades médicas defendem como princípios o credenciamento universal e a auto-regulação dos preços de suas atividades profissionais. Mas, a regulação governamental é considerada bem-vinda quando o Estado torna-se um fiador da manutenção de uma certa autonomia profissional, em moldes liberais.

A Agência Nacional de Saúde Suplementar (ANS), criada em 2001 como suporte institucional para operacionalizar a Lei 9656-98, tem como pauta de trabalho a definição de: regras de cobertura; reajustes de preços dos planos; normas sobre reservas técnicas e controle de solvência das empresas e o ressarcimento ao SUS. A partir do final de 2004, a ANS passou a utilizar indicadores de qualidade da assistência intermediada ou prestada diretamente pelas empresas de planos de saúde.

Esse processo de normatização enfrenta uma acirrada oposição de alguns segmentos do mercado de assistência privada à saúde. Os mais importantes jornais do País publicam sistematicamente artigos contra a legislação que regulamenta os planos de saúde, como por exemplo: o da Gazeta Mercantil (21/01/2005) cujo autor cobra que o governo flexibilize as coberturas dos planos e permita o aumento dos valores do co-pagamento e o do Estado de São Paulo (24/01/2005) criticando a Lei 9656-98 por suas coberturas mais abrangentes, ais caras e na maioria das vezes desnecessárias.

O ressarcimento ao SUS também é polêmico. Por um lado, a cobrança pelo SUS do uso de serviços públicos por clientes de planos de saúde tem sido avaliada como por gestores públicos, agências multilaterais, como o Banco Mundial e o BID e setores da sociedade civil como uma ferramenta adequada à obtenção de maior equidade no financiamento da saúde. Em contraste, as empresas de planos de planos de saúde e mais recentemente entidades de representação de hospitais privados consideram que cobrança de serviços (que são um direito de cidadania) é inconstitucional. Em outros casos, os posicionamentos contrários ao ressarcimento, ressaltam a inocuidade de tal instrumento de regulação em face da superioridade das coberturas das empresas de planos de saúde, inclusive no que se refere ao consumo de procedimentos de alto custo, relativamente àquelas propiciadas pelo SUS.

O Poder Legislativo e o Poder Judiciário vem influenciando fortemente a agenda de debates sobre o sub-sistema privado de saúde ao apresentar adendos e reinterpretar a legislação reguladora. 0 Legislativo responde às fortes pressões de prestadores de serviços. No momento tramita no Congresso Nacional uma Projeto Lei (PL $n^{\circ}$ 3.466/o4) propondo que a remuneração das empresas de planos de saúde aos seus prestadores de serviços tenha como referencia obrigatória a Classificação Brasileira Hierarquizada de Procedimento Médicos (CBHPM), dotando a ANS de poder para fiscalizar o cumprimento da norma. As empresas de planos de saúde justificam suas discordâncias, em relação às proposições sobre o poder de regulação dos valores de remuneração pelas próprias entidades, conferindo-lhes o atributo de "cartelizantes".

O Judiciário, nas primeiras instâncias, tem se posicionado inequivocamente ao lado dos consumidores, argüindo a natureza específica dos contratos que envolvem a saúde. As cortes superiores, responsáveis pelo exame das ações, em geral movidas pelas empresas de planos de saúde sobre a inconstitucionalidade de preceitos da Lei 9656 parecem menos permeáveis 
à uma intervenção mais extensa do Estado nos contratos de planos de saúde. O Supremo Tribunal Federal em 2003, ao declarar que os contratos dos planos anteriores, contendo restrições de coberturas, permaneciam vigentes, impôs um sério obstáculo à regulamentação.

Essas demandas, conflitos e instrumentos de regulação podem ser sinteticamente agrupados quanto a legitimidade da convocação ou não da intervenção estatal. Embora, os enunciados das proposições da agenda de debates do segmento privado reafirmem exaustivamente a condição autonomia todos os seus elementos. É importante sublinhar que a noção de liberdade de atuação das empresas do sub-sistema assistencial privado tem sido utilizada para justificar desde a decisão sobre a definição do perfil e capacitação tecnológica da oferta dos prestadores de serviços, bem como as concepções sobre a comercialização de planos com coberturas restritas, até a recente proposta das entidades médicas de regulamentar uma prática informal - a cobrança "por fora” de pacientes internados no SUS que possam remunerar um médico de sua escolha e a permanência em acomodações diferenciadas (CFM, 2005).

\section{Considerações Finais}

Entre as conseqüências da segmentação do sistema de saúde brasileiro podem ser elencadas: o elevado padrão de gastos privados com saúde (provenientes de despesas empresas empregadoras e das famílias); a transferência de riscos relacionados com custos assistenciais do privado para o público, incluindo a cobrança de atendimento direto às famílias, em função do padrão de competição e autonomia dos prestadores de serviços; o padrão diferenciado, segundo condição de cobertura, de utilização de serviços, no que se refere a quantidade de serviços consumidos e presumivelmente na qualidade da atenção prestada. Nesse complexo e fragmentado sistema, interesses, conflitos e consensos relacionados com as dimensões políticas, éticas, econômicas e assistenciais renovamse permanentemente.

As previsões sobre o futuro dos elementos que integram o sistema de saúde no Brasil são díspares. Esses prognósticos polares vem pautando agenda es- pecíficas e especializadas de debates e influenciando a formulação das políticas públicas. As percepções de atores diretamente envolvidos com interesses particulares, por vezes extraídas sem nenhuma mediação do cotidiano das experiências isoladas de cada elemento no sistema amplificam as tensões. A transformação das "informações" parciais em vetores de vocalização de interesses particulares em arenas específicas dificulta a construção de marcos analíticos mais realistas.

Nos últimos anos as expressões “ir para o SUS”, "cair no SUS" tornaram-se sinônimos de ameaça para os segmentos médios. Os argumentos variam desde as formulações sobre o potencial destrutivo do Estado em relação à eficiência do sistema privado até a apresentação da segmentação como um processo transitório de tamponamento social, que se justifica enquanto o SUS amadurece. Sob o primeiro registro, a universalização passou a ser entendida como extensão da escassez, má qualidade e destruição da capacitação tecnológica da medicina brasileira. A constatação de que a magnitude dos recursos financeiros, mobilizados pelos planos e seguros de saúde é semelhante ao orçamento do Ministério da Saúde estimula diagnósticos sombrios e a reiteração de proposições incrementais. Não é por menos que a única proposta de regulação das interfaces entre o público e o privado que adquire conteúdo legal é: o ressarcimento ao SUS contraria os preceitos do direito universal à saúde.

Os mais otimistas exibem as estatísticas sobre as melhorias do SUS, contendo dados sobre os atendimentos universais, como os transplantes e as terapias renais substitutivas. Os avanços referentes à arquitetura institucional da descentralização da saúde, que se tornaram modelares e hoje inspiram outras políticas sociais são evocados para demonstrar o quanto e o como o processo de implementação do SUS alterou as relações entre as esferas de poder e a sociedade civil. Após 15 anos, os instrumentos legais e as instituições destinados a substituir o modelo de atenção à saúde baseado no princípio contributivo e na centralização das decisões e dos recursos financeiros, pela organização de um sistema baseado no direito universal e na descentralização e hierarquização da assistência estão consolidados.

Os pressupostos e as proposições dos fóruns de 
debate mais abrangentes como a XII Conferência Nacional de Saúde (2003) consideram que as profundas desigualdades sócio-econômicas e culturais, as assimetrias interregionais, interestaduais, as características do próprio federalismo brasileiro e a persistência dos traços privatistas sobre o qual o sistema foi construído constituíram-se como obstáculos permanentes a implementação do SUS. Um dos principais desafios para o SUS, portanto é a resolução dos problemas histórico-estruturais do sistema de saúde, compatibilizando a afirmação da saúde como direito de cidadania nacional com o respeito a diversidade regional e local. Isso implica uma mudança substantiva no papel do Estado nas três esferas de governo, o fortalecimento da gestão pública com finalidades diferenciadas no âmbito nacional, estadual e municipal, a definição de competências para cada esfera de governo e o desenvolvimento de ações coordenadas, buscando articular princípios nacionais de política com decisões e parâmetros locais e regionais.

A retomada das diretrizes da Reforma Sanitária na XII Conferência Nacional de Saúde realizada em 2003 repõe o ebate da saúde no contexto dos direitos de cidadania e da conquista de uma democracia efetiva. Ainda assim, a regulação das interfaces entre o público e o privado no sistema de saúde não adquiriu o estatuto de tema da agenda de debates. As articulações e contraposições entre as políticas governamentais presumidamente destinadas a maximizar a equidade e aquelas voltadas à viabilização dos processos de acumulação de bens e serviços privados de saúde continuam pouco visíveis e quase sempre sombreadas por acepções sobre uma possível expansão do SUS regulada apenas pelo incremento de recursos financeiros.

Quinze anos após a criação do SUS, a distância entre as suas normas formais e seu funcionamento deve-se a limites estruturais econômico-financeiros, fartamente reconhecidos. A presença das instituições sancionadas informalmente, em todas as dimensões do sistema de saúde brasileiro é freqüentemente neglicenciada na análises das políticas públicas. A demarcação das fronteiras entre esfera pública e esfera privada não apenas pela percepção de suas demandas, mas também pelo mapeamento da representação de interesses privados pode contribuir para aproximar o País real do País formal.

\section{Referências}

Bahia, L et al. 2004. Cobertura de planos privados de saúde e doenças crônicas: notas sobre a utilização de procedimentos de alto custo. Ciência \& Saúde Coletiva, Rio de Janeiro, v. 9, n. 4, p. 921-929, 2004.

Banco Mundial 1993. Relatório sobre Desenvolvimento Social: investindo em saúde. Rio de Janeiro: Fundação Getúlio Vargas, 1993.

Boschi, R. e Lima, M.R de 2002. O Executivo e a construção do Estado no Brasil: do desmonte da era Vargas ao novo intervencionismo regulatório. In VIANNA, L.W. A democracia e os três poderes no Brasil. Belo Horizonte: UFMG; Rio de Janeiro: IUPERJ/FAPERJ, 2002.

FEDERAÇÃO NACIONAL DAS EMPRESAS DE SEGUROS PRIVADOS E DE CAPITALIZAÇÃO - FENASEG. Seguro saúde: guia para consulta rápida. Rio de Janeiro, 2003.

CONSELHO FEDERAL DE MEDICINA - CFM. O Médico e Seu Trabalho: aspectos metodológicos e resultados do Brasil. Brasília, DF, 2004.

JORNAL DO CONSELHO FEDERAL DE MEDICINA. Rio de Janeiro: CFM, n. 152, dez. 2004/jan. 2005.

CONSELHO NACIONAL DE SAÚDE - CNS. Relatório da XII Conferência Nacional de Saúde. 2005

INSTITUTO BRASILEIRO DE GEOGRAFIA E ESTATÍSTICA - IBGE. Pesquisa Assistência Médico-Sanitária. AMS/2002. Rio de Janeiro, 2002.

INSTITUTO BRASILEIRO DE GEOGRAFIA E ESTATÍSTICA - IBGE. Pesquisa Nacional por Amostra de Domicílios. PNAD/2003. Rio de Janeiro, 2004.

INSTITUTO BRASILEIRO DE GEOGRAFIA E ESTATÍSTICA - IBGE. Pesquisa de Orçamento Familiares. POF/2002-2003. Rio de Janeiro, 2004.

LIMA-COSTA M. F. et al. 2002. The Bambui Health and Aging Study (BHAS): private health plan and medical care utilization by older adults. Cadernos de Saúde Pública, Rio de Janeiro, v. 18, n. 1, p. 177-186, 2002.

BRASIL - Ministério da Previdência Social. Secretária da Previdência Social. Estimativas de cobertura realizadas a partir da análise dos microdados da Pesquisa Nacional por Amostra de Domicílios Instituto Brasileiro de Geografia e Estatística - 2003. Brasília, DF, 2004. 
BRASIL - Ministério da Saúde. Sistema de Informações de Informações sobre Orçamentos Públicos em Saúde - SIOPS. 2004.

ORGANIZAÇÃO MUNDIAL DA SAÚDE. Health system attainment and performance in all Member States, ranked by eight measures, estimates for 1997. In: . The World Health Report 20oo. Genebra: 2000.
ORGANIZAÇÃO MUNDIAL DA SAÚDE. The world health report 2004. Genebra, 2004.

UGÁ, M. A. et al. 2003. Descentralização e alocação de recursos no âmbito do Sistema Único de Saúde. Ciência \& Saúde Coletiva, Rio de Janeiro, v. 8, n. 2, p. 417-427, 2003.

Recebido em: 21/06/2005

Aprovado em: 13/07/2005

30 Saúde e Sociedade v.14, n.2, p.9-30, maio-ago 2005 